\title{
Compliance with Infection Control Practices among Healthcare Practitioners in Saudi Arabia during Coronavirus Pandemic: Cross-Sectional Study
}

\section{Saeed S Alqahtani}

Department of Surgery, Faculty of Medicine, Najran University, Najran, Kingdom of Saudi Arabia

Correspondence:

Dr. Saeed S Alqahtani

Department of Surgery,

Faculty of Medicine, Najran University,

Najran, Kingdom of Saudi Arabia

Email: saeedalqahtani641@gmail.com; Alhafezsaeed@gmail.com

\section{ABSTRACT}

Objective: Coronavirus infection is currently responsible for considerable morbidity and mortality in Saudi Arabia and across the globe. The aim of this study was to determine the level of compliance to infection control practices among healthcare practitioners in the Kingdom of Saudi Arabia.

Materials and Methods: This cross-sectional study was conducted with 180 healthcare practitioners working in military, university, government and private hospitals in four (4) regions in Saudi Arabia, namely, Riyadh, Najran, Abha and Al Baha. Samples were selected using convenience sampling. The study utilized the following statistical formula: percentage distribution, mean, standard deviation and analysis of variance (ANOVA).

Results: Most of the healthcare practitioners were young adults, male, licensed physicians, Saudi citizens, doctoral degree holders, have 1 to 5 years of hospital experience, work in university hospitals, and lastly were assigned to a medical ward. Healthcare practitioners in Saudi Arabia have high compliance with infection control $(x=3.45, S D \pm 0.28)$ and very high compliance with contact precaution practices $(x=3.45, S D \pm 0.82)$ during the time of coronavirus pandemic. There is no significant difference in compliance with infection control $(\mathrm{F}=\mathbf{0 . 3 4 0 4}, \mathrm{p}=\mathbf{0 . 7 9 6 3})$ and contact precaution practices $(F=0.3404, p=0.7963)$ among healthcare practitioners working in the different regions of Saudi Arabia.
Conclusion: Healthcare practitioners in Saudi Arabia usually comply to infection control practices and always comply with contact precaution. Also, health workers' infection control and contact precaution practices across Najran, Al Baha, Riyadh and Abha are the same and standardized.

Key words: compliance, infection control, hand hygiene. 


\section{Introduction}

The global battle to contain the novel coronavirus disease 2019 (COVID-19) pandemic rages on [1]. In the recent months, the World Health Organization (WHO) declared COVID-19 outbreak as a public health emergency of international concern. Coronavirus disease (COVID-19) is an infectious disease caused by a newly discovered coronavirus. Understanding its burden as an emerging infectious disease is vital for devising appropriate infection control strategies [2].

Coronavirus infection is currently responsible for considerable morbidity and mortality in Saudi Arabia and across the globe [2]. Nearly four months have passed since the emergence but even up to this date there are no specific vaccines or treatments for COVID-19 [3]. This lead to rapid spreading of the COVID19 pandemic. In this light, Saudi Arabia was among the first countries to implement early and unprecedented precautionary strict measures to prevent virus entry to the country or to mitigate its impact when it arrives. The country has taken prompt strict public health measures to control and prevent the spread of the outbreak. In fact, Saudi Arabia has imposed a number of extreme measures on social movement, social and religious gatherings, travel, and businesses way before the first COVID19 case was reported in the country [4].

Many infections acquired by patients can be spread by healthcare workers [5]. Health care workers can also act as reservoirs, harboring the microorganism for several days [6]. Thus, special attention should be addressed to health workers in hospital facilities as they play a significant role in disease transmission and healthcare-associated infections [1]. Transmission of healthcare-associated infections is still a major concern in point-ofcare [7]. In fact, infection-related complications remain to be one of the most commonly reported medical errors committed by healthcare staff [8]. It was estimated that around $20 \%$ to $40 \%$ of healthcare-associated infections have been attributed to cross-infection from the hands of health care personnel as one of the major sources of nosocomial pathogens. Contamination of the hands of health care personnel could in turn result from either direct patient contact or indirectly from touching contaminated environmental surfaces [9]. The National Safety and Quality Health Service (NSQHS) Standards even reiterated that healthcare practitioners must adhere to strategies that prevent and control infection. This can be achieved by prudent use of antimicrobials, adhering to standard precautions and wearing of personal protective equipment [10].

Thus, the researcher came up with a paper entitled "Compliance to Infection Control Practices among Staff Nurses in Saudi Arabia" to determine the level of compliance to infection control practices among healthcare practitioners in Saudi Arabia.

\section{Statement of the Problem}

In general, the researcher sought to determine compliance to infection control practices among healthcare practitioners in different tertiary hospitals in Saudi Arabia.

Specifically, it sought to answer the following questions:
1. What are the demographic characteristics of healthcare practitioners in terms of age, gender, profession, nationality, education, years of hospital experience, hospital setting, area of assignment, and facility location?

2. What is the level of compliance to infection control practices among healthcare practitioners during the coronavirus pandemic?

3. What is the level of compliance to contact precaution practices among healthcare practitioners during the coronavirus pandemic?

4. Is there a significant difference in compliance with infection control practices among healthcare practitioners in different regions in Saudi Arabia?

5. Is there a significant difference in compliance with contact precaution practices among healthcare practitioners in different regions in Saudi Arabia?

\section{Materials and Methods}

This cross-sectional study was conducted in the following regions in Saudi Arabia, namely, Riyadh, Najran, Abha and Al Baha. The study was conducted simultaneously at one fixed point in time. Data collection was conducted at the time of coronavirus pandemic over a 4-month period from the months of March to May 2020. The study included a total of 180 healthcare practitioners (physicians, nurses, medical laboratory technician, and hospital administrators) as respondents of the study. Samples were selected using convenience sampling. Data gathering took place in selected military, university, government and private hospitals in different regions in the Kingdom of Saudi Arabia. Bioethical principles were strictly observed and implemented in the study. The respondents' rights and protection were taken into consideration throughout the conduct of the study. The observational data were entered into a Microsoft Excel database. Descriptive and inferential analysis were performed with Excel office with 95\% confidence intervals. The study utilized the following statistical formula: percentage distribution, mean, standard deviation and analysis of variance (ANOVA).

A structured survey questionnaire was provided to the respondents of the study. Healthcare practitioners were asked to complete the survey tool within 15 to 20 minutes. The Compliance to Key Performance Indicator (KPI) for Infection Control Tool was adapted from the Australian Commission on Safety and Quality in Healthcare [10]. The researcher utilized a 4point Likert scale using the following rating scales: " 3 " which denotes always, "2" means sometimes, and " 1 " for never. In addition, the researchers have utilized Contact Precaution Monitoring Tool which was adapted from the Infection Control Program of the World Health Organization [3]. The use of contact precaution tool was used to monitor healthcare practitioners' compliance with hand washing practices in any of the following opportunities: before patient contact, before aseptic procedure, after body fluid exposure, after patient contact, and lastly after touching patient's surroundings. The said checklist tool was rated "4" for always, " 3 " for sometimes, "2" for seldom and " 1 " for never. Both research instruments were tested for content validity and construct validity by three (3) experts in the healthcare field. The said tools underwent a pilot study 
on 20 hospital staff working in Najran University Hospital. The tools were tested for reliability and internal consistency. All research tools obtained a 0.78 and 0.85 Cronbach alpha reliability score and were considered acceptable and have a good internal consistency, respectively [11].

\section{Results}

Table 1 depicts the demographic characteristics of healthcare practitioners as respondents of the study. Based on the data analysis performed, with a total of 180 respondents, it was found that most of the healthcare practitioners were young adults $(n=112$ or $62.2 \%)$, male $(n=132$ or $73.3 \%)$, licensed physicians $(\mathrm{n}=117$ or $65.0 \%$ ), Saudis $(\mathrm{n}=120$ or $66.7 \%)$, doctoral degree holders ( $\mathrm{n}=126$ or $70.0 \%$ ), have 1 to 5 years of hospital experience ( $\mathrm{n}=79$ or $43.9 \%$ ), working in university hospitals $(n=61$ or $33.9 \%)$, were assigned to a medical ward $(n=66$ or $36.7 \%$ ), and lastly came from Abha region in Saudi Arabia $(n=62$ or $34.4 \%)$.

Table 2 shows that the majority of healthcare practitioners perceived they have "high compliance" to infection control practices in terms of: wearing personal protective equipment $(x=2.38, S D \pm 0.69)$, use alcohol-based hand rubs and sanitizers $(x=2.24, S D \pm 0.97)$ and adhere to strict application to infection control policy $(x=2.23, \mathrm{SD} \pm 0.77)$. Similarly, respondents displayed "very high compliance" in being aware of infection control policy in their respective hospitals $(\mathrm{x}=2.88, \mathrm{SD} \pm 0.40)$, and perceive infection control policy is a crucial factor in controlling infections $(\mathrm{x}=2.81, \mathrm{SD} \pm 0.42)$. On the contrary, healthcare practitioners in Saudi Arabia demonstrated "moderate compliance" in wearing personal protective equipment $(\mathrm{x}=2.10$, $\mathrm{SD} \pm 0.83)$, "low compliance score" in using antimicrobial soap with running water $(\mathrm{x}=1.57, \mathrm{SD} \pm 0.80)$, and "very low compliance" in attending seminars and workshop about infection control $(\mathrm{x}=1.38, \mathrm{SD} \pm 0.72)$.

Table 3 shows compliance with contact precaution practices among healthcare practitioners during the time of the coronavirus pandemic. . Accordingly, the findings of this study revealed that most of the healthcare practitioners in Saudi Arabia have "very high compliance" ( $\mathrm{x}=3.45, \mathrm{SD} \pm 0.82)$ with contact precaution practices during the coronavirus pandemic. Specifically, the majority of healthcare practitioners perceived they have "very high compliance" with contact precaution after touching the patient $(x=3.44, S D \pm 0.90)$, after exposure to patients' body fluid $(x=3.85, \mathrm{SD} \pm 0.45)$ and before performing aseptic procedures $(x=3.67, \mathrm{SD} \pm 0.73)$. On the other hand, healthcare practitioners only have "high compliance level" with contact precaution before patient contact $(\mathrm{x}=3.16, \mathrm{SD} \pm 0.95)$, and after touching patients' surroundings $(\mathrm{x}=3.13, \mathrm{SD} \pm 1.06)$.

Table 4 depicts the test of significant difference in the level of compliance to infection control practices among healthcare practitioners in the different regions of Saudi Arabia. Analysis of Variance (ANOVA) One-way factor revealed no significant difference $(\mathrm{F}=0.3404, \mathrm{p}=0.7963)$ in compliance with infection control practices among healthcare practitioners working in the different regions of Saudi Arabia. Thus, health workers' infection control practices across Najran, Al Baha, Riyadh and Abha are the same and standardized.
Table 5 depicts the test of significant difference in the level of compliance with contact precaution practices among healthcare practitioners in the different regions of Saudi Arabia. Analysis of Variance (ANOVA) One-way factor revealed no significant difference $(\mathrm{F}=0.3404, \mathrm{p}=0.7963)$ in compliance with contact precautions among healthcare practitioners working in the different regions of Saudi Arabia. Thus, health workers' contact precaution practices across Najran, Al Baha, Riyadh and Abha are the same and standardized.

\section{Discussion}

Most of the healthcare practitioners were young adults, male, licensed physicians, Saudi citizens, doctoral degree holders, have 1 to 5 years of hospital experience, work in university hospitals, were assigned to a medical ward, and lastly came from Abha region in Saudi Arabia. Most healthcare practitioners were young adults which is the expected age bracket for newly graduated healthcare practitioners who just secured a professional license and are beginning a professional career as healthcare practitioners. These age groups are more eager to work, can perform multitasking, and can work under pressure which can create a significant impact during their professional practice in their respective clinical work settings. Moreover, the results also suggest that registered healthcare practitioners are relatively younger and were assumed to be more receptive to the challenges of infection control practices [12]. Most healthcare practitioners were doctoral degree holders being their highest education attained. Tanner [13] notes that healthcare practitioners with higher degrees are especially well-suited in meeting complex healthcare demands, reducing patient risk, and lowering mortality. Thus, proceeding to higher education will enhance and guide the competence of hospital staff in formulating, implementing and evaluating evidence-based patient care that will improve infection control. Most healthcare practitioners have 1 to 5 years of hospital experience. A study by Altuntas \& Baykal [14] emphasizes that newly licensed practitioners entering the health care facilities demonstrate little involvement, but are necessitated to assume full responsibility for patient care. Furthermore, this creates a labor difficulty and job annoyance which can drastically affect patient care and organizational commitment practices. Most healthcare practitioners were assigned to a medical ward. The high rates of selfreported compliance score among hospital staff are consistent with previous hospital areas of assignment that also indicated high rates of self-reported compliance with infection control practices [5]. Most healthcare practitioners worked in Abha province in Saudi Arabia. A study in United States showed that healthcare workers practicing in rural health care facilities had $40 \%$ decreased certification in infection control than those healthcare workers who practiced in urban health care facilities. Accordingly, there was a statistically significant decreased certification within suburban areas, but statistical findings revealed that healthcare facility location was not a significant predictor of certification for an infection control program [15].

The majority of healthcare practitioners in Saudi Arabia have "high compliance level" to infection control practices during the coronavirus pandemic. This implies that hospital staff often practice measures that prevent and control infection. Such findings of the study are supported by studies in Philippines, 
Table 1: Demographic Characteristics of Healthcare Practitioners as Respondents of the Study

\begin{tabular}{|c|c|c|}
\hline Demographic Characteristics & $\begin{array}{c}\text { Frequency } \\
\text { (n) }\end{array}$ & $\begin{array}{c}\text { Percentage } \\
(\%)\end{array}$ \\
\hline \multicolumn{3}{|l|}{ A. Age } \\
\hline $21-35$ years old (Young adults) & 112 & 62.2 \\
\hline $36-55$ years old (Middle adults) & 48 & 26.7 \\
\hline $56-65$ years old (Late adults) & 20 & 11.1 \\
\hline \multicolumn{3}{|l|}{ B. Gender } \\
\hline Male & 132 & 73.3 \\
\hline Female & 48 & 26.7 \\
\hline \multicolumn{3}{|l|}{ C. Profession } \\
\hline Medical Doctor & 117 & 65.0 \\
\hline Nurses & 46 & 25.6 \\
\hline Healthcare Administration & 7 & 3.9 \\
\hline Medical Laboratory & 10 & 5.5 \\
\hline \multicolumn{3}{|l|}{ D. Nationality } \\
\hline Saudi & 120 & 66.7 \\
\hline $\begin{array}{l}\text { Non-Saudi (Sudanese, Filipino, } \\
\text { Indian, Egyptian, Yemeni, British) }\end{array}$ & 60 & 33.3 \\
\hline \multicolumn{3}{|l|}{ E. Education } \\
\hline Diploma & 8 & 4.4 \\
\hline Bachelor & 31 & 17.2 \\
\hline Master & 15 & 8.3 \\
\hline Doctoral & 126 & 70.0 \\
\hline \multicolumn{3}{|l|}{ F. Years of Hospital Experience } \\
\hline$<1$ year (novice) & 15 & 8.3 \\
\hline 1 to 5 years (advanced beginner) & 79 & 43.9 \\
\hline 6 to 10 years (competent) & 55 & 30.6 \\
\hline 11 to 20 years (profident) & 25 & 13.8 \\
\hline$\geq 20$ years (expert) & 6 & 3.3 \\
\hline \multicolumn{3}{|l|}{ G. HospitalSetting } \\
\hline University Hospital & 61 & 33.9 \\
\hline Military Hospital & 49 & 27.2 \\
\hline Ministry of Health Hospital & 57 & 31.7 \\
\hline Private Hospital & 13 & 7.2 \\
\hline \multicolumn{3}{|l|}{ H. Area of assignment } \\
\hline Generalward & 62 & 34.4 \\
\hline Medical ward & 66 & 36.7 \\
\hline Pediatric ward & 35 & 19.4 \\
\hline Intensive care unit & 17 & 9.4 \\
\hline \multicolumn{3}{|l|}{ I. Facility Location } \\
\hline Riyadh & 54 & 30.0 \\
\hline Najran & 35 & 19.5 \\
\hline Abha & 62 & 34.4 \\
\hline Al Baha & 29 & 16.1 \\
\hline TOTAL & $\mathrm{N}=180$ & $100.0 \%$ \\
\hline
\end{tabular}


Table 2: Compliance with Infection Control Practices among Healthcare Practitioners in Saudi Arabia

\begin{tabular}{|c|c|c|c|}
\hline Infection Control Practices & $\begin{array}{l}\text { Mean } \\
(n=180)\end{array}$ & SD & Level of Compliance \\
\hline A. Statements & & & \\
\hline $\begin{array}{l}\text { 1. Wear personal protective equipment (PPE) like } \\
\text { gloves, gown, mask }\end{array}$ & 2.38 & 0.69 & High Compliance \\
\hline $\begin{array}{l}\text { 2. Timely use of alcohol-based hand rubs and } \\
\text { sanitizers. }\end{array}$ & 2.24 & 0.97 & High Compliance \\
\hline 3. Use antimicrobial soap with running water & 1.57 & 0.80 & Low Compliance \\
\hline 4. Compliance with hand hygiene protocols. & 2.10 & 0.83 & Moderate Compliance \\
\hline $\begin{array}{l}\text { 5. Awareness and understanding about the } \\
\text { infection control policy inyour hospital. }\end{array}$ & 2.88 & 0.40 & Very High Compliance \\
\hline $\begin{array}{l}\text { 6. Perceive infection control policy as cruaal } \\
\text { factorin controlling infections. }\end{array}$ & 2.81 & 0.42 & Very High Compliance \\
\hline $\begin{array}{l}\text { 7. Attended infection control programs like } \\
\text { seminar, workshop, training. }\end{array}$ & 1.38 & 0.72 & Very Low Compliance \\
\hline $\begin{array}{l}\text { 8. Strict application of infection control policy in } \\
\text { the work setting. }\end{array}$ & 2.23 & 0.77 & High Compliance \\
\hline TOTAL & 2.21 & 0.70 & High Compliance \\
\hline
\end{tabular}

Legend: 1.00-1.40 Very low compliance; 1.41-1.80 Low compliance; 1.81-2.20 Moderate compliance; 2.21-2.60 High compliance; and 2.61-3.00 Very high compliance

Table 3: Compliance with Contact Precautions among Healthcare Practitioners in Saudi Arabia

\begin{tabular}{lcc}
\hline Infection Control Practices & $\begin{array}{c}\text { Mean } \\
(n=180)\end{array}$ & SD Level of Compliance \\
\hline
\end{tabular}

\section{A. Statements}

1. Before patient contact

2. After touchingthe patient

3.16 $\quad$ High Compliance

3. After body fluid exposure

4. After touchingpatients' surroundings

5. Before an aseptic procedure

TOTAL

$\begin{array}{ccc}3.44 & 0.90 & \text { Very High Compliance } \\ 3.85 & 0.45 & \text { Very High Compliance } \\ 3.13 & 1.06 & \text { High Compliance } \\ 3.67 & 0.73 & \text { Very High Compliance } \\ 3.45 & 0.82 & \text { Very High Compliance }\end{array}$

Legend: 1.00-1.60 Very low compliance; 1.61-2.20 Low compliance; 2.21-2.80 Moderate compliance; 2.81-3.40 High compliance; and 3.41-4.00 Very high compliance 
Table 4: Test of Significant Difference in the Level of Compliance with Infection Control Practices among Healthcare Practitioners in Different Regions in Saudi Arabia

\begin{tabular}{|c|c|c|c|c|c|c|}
\hline \multicolumn{2}{|l|}{ Groups } & Count & Sum & Average & \multicolumn{2}{|c|}{ Variance } \\
\hline Najran & & 8 & 17.16 & 2.145 & & 93114286 \\
\hline Al Baha & & 8 & 16.76 & 2.095 & & 0.297 \\
\hline Riyadh & & 8 & 18.79 & 2.34875 & & 24498214 \\
\hline Abha & & 8 & 17.17 & 2.14625 & & 76598214 \\
\hline \multicolumn{7}{|c|}{ Analysis of Variance (ANOVA): One-Way Factor } \\
\hline Source of Variation & SS & df & MS & $\mathrm{F}$ & P-value & F crit \\
\hline Between Groups & 0.304075 & 3 & 0.101358333 & 0.340354002 & $0.796296868^{\circ}$ & 2.946685266 \\
\hline Within Groups & 8.338475 & 28 & 0.297802679 & & & \\
\hline Total & 8.64255 & 31 & & & & \\
\hline
\end{tabular}

*p-value is significant if $\mathrm{p}<.05$

Table 5.:Test of Significant Difference in the Level of Compliance with Infection Control Practices among Healthcare Practitioners in Different Regions in Saudi Arabia

\begin{tabular}{|c|c|c|c|c|c|c|}
\hline Groups & & Count & Sum & Average & Variance & \\
\hline Najran & & 5 & 17.39 & 3.478 & 0.11572 & \\
\hline Al Baha & & 5 & 15.72 & 3.144 & 0.15983 & \\
\hline Riyadh & & 5 & 18.7 & 3.74 & 0.03445 & \\
\hline Abha & & 5 & 16.63 & 3.326 & 0.14858 & \\
\hline \multicolumn{7}{|c|}{ Analysis of Variance (ANOVA): One Way Factor } \\
\hline Source of Variation & SS & Df & MS & $\mathrm{F}$ & P-value & $\mathrm{F}$ crit \\
\hline Between Groups & 0.9538 & 3 & 0.317933333 & 2.773198424 & $0.07529116^{\circ}$ & 3.238871517 \\
\hline Within Groups & 1.83432 & 16 & \multirow[t]{2}{*}{0.114645} & & & \\
\hline Total & 2.78812 & 19 & & & & \\
\hline
\end{tabular}

$* \mathrm{p}$-value is significant if $\mathrm{p}<.05$ 
Bangladesh, and United States. Accordingly, hospital staff have a high compliance score to key performance indicators for patient safety outcomes in terms of infection control [16]. A study in Bangladesh shows a significant improvement in the infection control practices among health practitioners [17]. Furthermore, anecdotal reports from management showed statistical significant improvements in healthcare worker's compliance with basic infection control practices [18]. Controlling healthcare-associated infections and strict compliance with infection control standards among healthcare practitioners is imperative. Preventing the patient from acquiring infections in the healthcare facilities can reduce potential harm, comorbidities and achieve favorable health outcomes for the patients. Although healthcare practitioners have high compliance with infection control, it was observed that hospital staff demonstrated low compliance scores in the following: a) using antimicrobial soap with running water for hand washing and b) attending seminars and workshop about infection control. It must be known that cleaning hands with antimicrobial soap and running water is an effective way to prevent the transmission of disease-causing microorganisms [19]. When health care workers do not follow appropriate infection control measures, their hands and clothing can easily become contaminated [6]. Hand hygiene is a fundamental infection control strategy for the prevention of pathogen transmission in healthcare facilities [20]. Thus, the success of hand hygiene programs depends on high compliance rate among hospital staff [21].

Most of the healthcare practitioners in Saudi Arabia have "very high level of compliance" to hand hygiene protocols during coronavirus pandemic. Similarly, a study by Garcell et al. [22] cited that high hand hygiene compliance score (91.6\%) was observed among nurses in Qatar. The highest compliance score was observed after blood and body fluid exposure $(80.0 \%)$ and after patient contact $(85.5 \%)$. On the contrary, a study in China reported that adherence to hand hygiene recommendations among healthcare workers remains suboptimal with a compliance rate of 30\% [23]. Hand hygiene is known as a fundamental and essential tool for reducing healthcare-acquired infections [24]. Careful adherence to hand hygiene before and after patient contact is needed by healthcare personnel to further protect themselves and patients [25]. Failure to adhere to proper hand hygiene practices is thought to be the leading cause of transmission of cross-infections [26]. Microbial infection and colonization can occur when pathogens are transferred from the hands of healthcare workers to the environment and to patients [20]. Regular hand hygiene is proven effective in killing microorganisms on hands. According to the National Health Service (NHS) in the United Kingdom, hand hygiene is the simple, most cost-effective and important strategy for the prevention of the spread of infection [22,27]. Lastly, the best way to prevent and slow down transmission is to be well-informed about the coronavirus (COVID-19) virus, the disease it causes and how it spreads. This can be achieved by protecting oneself and others from infection by performing hand washing or hand hygiene meticulously [3].
There is no statistically significant difference in compliance to infection control and hand hygiene practices among healthcare practitioners working in the different regions of Saudi Arabia. The study finding is contradicted by a study in Australia. Accordingly, compliance among healthcare workers have shown highly variable rates from below $50 \%$ to close to $90 \%$. Although the National Hand Hygiene Initiative was overwhelmingly successful in the majority of the states in Australia as it was associated with decreased infection rates but it seems that it is counter-productive and had quite a different result in South Australia. The disruption in infection control practices in South Australia showed a significant increase in infection rates. The difference is attributed to shifting away from other infection control programs and resources resulting in unintended consequences [19]. These differences in hand hygiene practices and standard precautions could be due to the variations by country and healthcare settings [5]. Infection control and hand hygiene practices among healthcare practitioners should be standardized across the globe regardless of the regions, resources, and facilities. The 2014 Society for Healthcare Epidemiology of America (SHEA) even cited that hand hygiene is a key strategy which is essential in breaking the transmission cycle from healthcare workers, patients and the environment [20]. Meanwhile, a study has observed that there is a wide variation in the scope and lacks detail of infection control guidelines. The need to develop national guidelines that provide a legally binding framework for the healthcare facility and training for infection prevention needs to be implemented in healthcare institutions of their respective countries. Harmonizing infection control programs rely on common taxonomy, state-of-the-art guidelines, and health recommendations from various countries. Currently, there is no harmonized guidelines and protocols on the most important healthcare-associated infections topics and infection control strategies [28]. Thus, the success of the programs depends primarily on a high compliance rate to infection control and standardized infection prevention practices among hospital staff [21].

\section{Conclusions}

Healthcare practitioners in Saudi Arabia usually comply with infection control practices and always comply with contact precaution at this time of pandemic. Also, health workers' infection control and hand hygiene practices across Najran, Al Baha, Riyadh and Abha are the same and standardized. An infection control training program is recommended in future research to improve strict compliance of healthcare professionals to infection control practices like hand hygiene, use of personal protective equipment, and contact precaution among others. Comprehensive infection control measures should be emphasized, demonstrated, and implemented by hospital staff in each clinical area of assignments. Thus, the need to develop competencies among healthcare practitioners in complying with infection control practices must be strictly emphasized especially during this time of coronavirus pandemic. It is clear that additional work is required to address the noncompliance rate to hand hygiene initiatives among some health care staff working in hospitals. 


\section{Acknowledgements}

Special appreciation to all healthcare practitioners from Abha, Al Baha, Najran, and Riyadh who participated in the study.

\section{References}

1. Y. M. Alsofayan, S. M. Althunayyan, A. A. Khan, A. M. Hakawi, and A. M. Assiri. "Clinical Characteristics of COVID19 in Saudi Arabia: A National retrospective study”, J. Infect. Public Health, 2020, 13, 920-925.

2. R. M. Al-Raddadi, O. I. Shabouni, Z. M. Alraddadi, A. H. Alzalabani, A. M. Al-Asmari, A. Ibrahim, A. Almarashi, and T. A. Madani. "Burden of Middle East respiratory syndrome coronavirus infection in Saudi Arabia", J. Infect. Public Health, 2020, 13, 692-696.

3. World Health Organization. "Coronavirus health topic,", WHO, 2020, https://www.who.int/health-topics/ coronavirus\#tab=tab_3 (Accessed: September 2020).

4. A. Algaissi, N. K. Alharbi, M. Hassanain, and A. Hashem. "Preparedness and response to COVID-19 in Saudi Arabia: Building on MERS experience", J. Infect. Public Health, 2020, $13,834-838$.

5. D. Russell, D. W. Dowding, M. V. McDonald, V. Adams, R. J. Rosati, E. L. Larson, and J. Shang. "Factors for compliance with infection control practices in home healthcare: findings from a survey of nurses' knowledge and attitudes toward infection control”, Am. J. Infect. Control, 2018, 46, 1211-1217.

6. A. Z. Feliciano, E. E. Feliciano, J. R. D. Feliciano, Z. S. Fernandez, P. C. G. Mejia, M. R. L. Diamla, S. Devkota, A. Y. Boshra, M. T. S. Cabanayan, et al. "Philippine professional core competencies' impact on nurses' key performance indicators for patient safety outcomes", Int. J. Adv. Appl. Sci., 2019, 7, $1-5$.

7. A. M. West, P. J. Teska, C. B. Lineback, and H. F. Oliver. "Strain, disinfectant, concentration, and contact time quantitatively impact disinfectant efficacy", Antimicrob. Resist. Infect. Control, 2018, 7, https://doi.org/10.1186/s13756018-0340-2.

8. P. C. G. Mejia, B. J. L. Breboneria, H. K. Pangandaman, J. S. Sadang, B. Hengnalen, J. M. Calaycay, N. D. Mala, A. M. Estanislao, R. L. Diamla, et al. "Student nurses' leadership and management competencies and key performance indicators (KPIs) for patient safety outcomes in Nakhon Pathom, Thailand", Int. J. Adv. Appl. Sci., 2020, 7, 113-120.

9. W. A. Rutala and D. J. Weber. "Disinfection and sterilization: An overview”, Am. J. Infect. Control, 2013, 41, S2-S5.

10. ACSQH, "Australian Commission on Safety and Quality in Health Care. Entity Resources and Planned Performance.," Australia.

11. D. F. Polit and C. T. Beck, Essentials of Nursing Research Appraising Evidence for Nursing Practice, 8th ed. Scientific Research Publishing, Philadelphia.
12. J. M. Sadang, J. K. Rajan, B. J. L. Breboneria, P. C. G. Mejia, A. Albougami, N. D. M. , Jehan Y. ElRazkey4, 5, R. N. Almario6, N. E. Bandera7, J. M. Macalipot7, et al. "The influence of social media usage on the academic performance of nursing students", Int. J. Heal. Med. Curr. Res., 2019, 4, $1527-1535$.

13. R. C. Tanner, "Long-term care issue brief: nursing home staffing standards: year end report-2004," https://pubmed.ncbi. nlm.nih.gov/15747436/ (Accessed: September 2020).

14. S. Altuntas and U. Baykal. "Relationship between nurses' organizational trust levels and their organizational citizenship behaviors", J. Nurs. Scholarsh., 2010, 42, 186-194.

15. E. L. Kalp, J. J. Harris, and G. Zawistowski. "Predictors of certification in infection prevention and control among infection preventionists: APIC MegaSurvey findings", Am. J. Infect. Control, 2018, 46, 858-864.

16. A. Z. Feliciano, E. E. Feliciano, P. C. G. Mejia, A. Y. Boshra, J. R. D. Feliciano, A. Osman, M. C. Malabanan, H. Alsharyah, Y. Hussein, et al. "Exploring the practices employed by nurses in stethoscope care", Int. J. Allied Med. Sci. Clin. Research, 2020, 7, 385-395.

17. L. Ara, F. Bashar, M. E. Tamal, N. A. Siddiquee, S. N. Mowla, and S. A. Sarker. "Transferring knowledge into practice: a multi-modal, multi-center intervention for enhancing nurses' infection control competency in Bangladesh", J. Hosp. Infect., 2018, 1-7.

18. J. McFarlin, T. H. Williamson, B. J. Gray, K. R. Hartless, A. L. Smith, and M. Moseley. "Behavior change for improved hand hygiene compliance: Engaging staff in learning", Clin. Key, 2008, 36, 160-161.

19. A. G. Barnett, K. Page, M. Campbell, D. Brain, and E. Martin. "Changes in healthcare- asoociated infections after the introduction of a national handy hygiene initiative", Healthc. Infect., 2014, 19, 128-134.

20. D. Calfee, C. Salgado, A. M. Milstone, A. Harris, D. Kuhar, J. Moody, K. Aureden, S. Huang, L. Maragakis, et al. "Strategies to prevent methicillin-resistant Staphylococcus aureus transmission and infection in acute care hospitals.", Infect. Control Hosp. Epidemiol., 2014, 35, https://doi. org/10.1086/676534.

21. D. Cantrell, O. Shamriz, M. J. Cohen, Z. Stern, C. Block, and M. Brezis. "Hand hygiene compliance by physicians: marked heterogeneity due to local culture?", Am. J. Infect. Control, 2009, 37, 301-305.

22. H. G. Garcell, A. V. Arias, F. R. Miranda, and R. R. Jimenez. "Observation of hand hygiene can show difference in staff compliance: Do we need to evaluate the accuracy for patient safety?", Qatar Med. J., 2017, 1, 1-6.

23. X. Mu, Y. Xu, T. Yang, J. Zhang, C. Wang, W. Liu, J. Chen, L. Tang, and H. Yang. "Improving hand hygiene compliance among healthcare workers: An interventional study in a hospital in Guizhou Province, China”, Brazilian J. Infect. Dis., 2016, 20, 413-318. 
24. M. Chakravarthy, S. N. Myatra, V. D. Rosenthal, F. E. Udwadia, B. N. Gokul, J. V. Divatia, A. Poojary, R. Sukanya, R. Kelkar, et al. "The impact of the International Nosocomial Infection Control Consortium (INICC) multicenter, multidimensional hand hygiene approach in two cities of India", J. Infect. Public Health, 2015, 8, 177-186.

25. A. Ghorbani, L. Sadeghi, A. Shahrokhi, A.

Mohammadpour, M. Addo, and E. Khodadadi. "Hand hygiene compliance before and after wearing gloves among intensive care unit nurses in Iran", Am. J. Infect. Control, 2016, 44, e279-e281.

26. S. McCalla, M. Reilly, R. Thomas, and D. McSpedon-Rai. "An automated hand hygiene compliance system is associated with improved monitoring of hand hygiene", Am. J. Infect. Control, 2017, 45, 492-497.

27. M. Mortell, H. H. Balkhy, E. B. Tannous, and M. T. Jong. "Physician 'defiance' towards hand hygiene compliance: Is there a theory-practice-ethics gap?", J. Saudi Hear. Assoc., 2013, 25, 203-208.

28. W. Zingg, N. T. Mutters, S. Harbarth, and A. W. Friedrich. "Education in infection control: A need for European certification”, Clin. Microbiol. Infect., 2015, 21, 1052-1056. 